\title{
Nitrogen multiple breath washout test for infants with cystic fibrosis
}

\begin{abstract}
To the Editor:
Multiple breath washout test (MBW) with lung clearance index (LCI) as a main outcome parameter has proven to be a valuable research tool in patients with cystic fibrosis (CF) [1,2]. Moreover, there is growing evidence of its relevance in routine clinical practice [3]. Nevertheless, some technical limitations remain that hamper its widespread use. While most of the MBW data in infants have been acquired via sulfur hexafluoride washout $\left(\mathrm{SF}_{6}-\mathrm{MBW}\right)$, the nitrogen variant $\left(\mathrm{N}_{2}-\mathrm{MBW}\right)$ is recommended by the European Cystic Fibrosis Society Clinical Trial Network (ECFS-CTN) for older children. However, this methodological discrepancy may limit long-term follow-up of cystic fibrosis patients because $\mathrm{N}_{2}-$ and $\mathrm{SF}_{6}-\mathrm{MBW}$ cannot be used interchangeably. In infants, the $\mathrm{N}_{2}-\mathrm{MBW}$ has not been fully investigated to date.
\end{abstract}

We report our data regarding safety, feasibility and repeatability of $\mathrm{N}_{2}-\mathrm{MBW}$ in cystic fibrosis infants. Between January 2015 and January 2017, we performed lung function testing in 35 infants aged 6.725.2 months (median 14.7) with classical form of cystic fibrosis. Testing was performed in patients without any signs of acute respiratory infection for at least 14 days. Quiet sleep was induced by administering chloral hydrate $80-100 \mathrm{mg} \cdot \mathrm{kg}^{-1}$ per rectum. The patients were placed in a supine position with their head and neck in a neutral position, and a Rendell-Baker face mask Nr. 1 or 2 (selected to keep the instrument dead space under $2 \mathrm{~mL} \cdot \mathrm{kg}^{-1}$ ) was tightly sealed around the mouth and nose. At first, $\mathrm{N}_{2}-\mathrm{MBW}$ was performed using the Exhalyzer D device (Ecomedics, Duernten, Switzerland) with the Spiroware 3.2.0 software, following all the relevant recommendations $[4,5]$. When finished, at least $120 \mathrm{~s}$ of medical air breathing followed (normalisation of breath pattern, nitrogen back wash-in). Afterwards, $\mathrm{SF}_{6}-\mathrm{MBW}$ was performed using the same device and software within a subgroup of 10 patients, who were tested after March 2016 ( $\mathrm{SF}_{6}-\mathrm{MBW}$ became available in our centre); their anthropometric parameters and age were not significantly different from those of the whole study group. Both measurements were performed in fixed order within the same sedation period and without changing the body and face mask position. The technical acceptability of trials was assessed by a physician with ECFS-CTN certification in this method and adhered to the standard operating procedure for $\mathrm{N}_{2}-\mathrm{MBW}$ [5] modified for infants and $\mathrm{SF}_{6}-\mathrm{MBW}$. Both tests were repeated at least three times to obtain a coefficient of variation $(\mathrm{CV})$ lower than $10 \%$. Pulse rate and haemoglobin oxygen saturation were continuously monitored during MBW measurements and until full consciousness was regained. A pair-wise t-test was used to compare results from $\mathrm{SF}_{6}{ }^{-}$and $\mathrm{N}_{2}-$ MBW in individual patients with both measurements available $(n=8)$. Patient's characteristics between the $\mathrm{N}_{2}-\mathrm{MBW}$ and $\mathrm{SF}_{6}-\mathrm{MBW}$ group were compared by the t-test. The reliability of $\mathrm{N}_{2}-\mathrm{MBW}$ was assessed using estimates of intraclass correlation (ICC). Coefficient of repeatability was calculated as follows: $1.96 \times \sqrt{2} \times$ within-subject standard deviation (SD). Calculations of repeatability and reliability data were based on appropriate one-way ANOVA models and performed on $\mathrm{N}_{2}-\mathrm{MBW}$ data only $(\mathrm{n}=23)$.

The feasibility of both tests in infants was high. Sedation with chloral hydrate failed in five patients (14.3\%). The success rate of $\mathrm{N}_{2}-\mathrm{MBW}$ reached $76.7 \%$ (23 successful measurements in 30 sedated infants), while, in $\mathrm{SF}_{6}-\mathrm{MBW}$, it reached $80.0 \%$. Irregular breathing pattern and face mask leaks were the most common reasons for data rejection. Mean number of trials performed per patient was 3.6 (range 3-6) resulting in 2.5 successful trials (range 2-4). Mean estimated duration of one $\mathrm{N}_{2}-\mathrm{MBW}$ trial was 3:57 min; $\mathrm{SF}_{6}-\mathrm{MBW}$ trial took 2:44 min on average. $\mathrm{N}_{2}-\mathrm{MBW}$ yielded higher values of FRC (functional residual capacity), LCI2.5 and LCI5 (defined as the number of lung volume turnovers required to decrease the inert gas concentration to $2.5 \%$ and $5 \%$ of its starting concentration, respectively) and lower values of tidal

@ERSpublications

Nitrogen multiple breath washout test is a safe, feasible and repeatable method for infants with cystic fibrosis. It may outperform sulfur hexafluoride variant with respect to its better suitability for long time follow up and lower technical demands. http://ow.ly/hqnB30k9REW

Cite this article as: Koucký V, Skalická V, Pohunek P. Nitrogen multiple breath washout test for infants with cystic fibrosis. Eur Respir J 2018; 52: 1800015 [https://doi.org/10.1183/13993003.00015-2018]. 
volume $(V \mathrm{~T})$. Respiratory rate $(\mathrm{RR})$ and ratio of time to peak expiratory flow to expiratory time (tPTEF/tE) did not differ between the two methods. Both reliability and repeatability of $\mathrm{N}_{2}-\mathrm{MBW}$ measurements was high with ICC exceeding 0.9 for most of the parameters; for detailed results see table 1 . We did not observe any adverse reactions such as haemoglobin desaturation $<94 \%$, apnoea, tachycardia, aspiration or prolonged sedation.

Our work is one of the two reports offering direct comparison of $\mathrm{N}_{2}-$ and $\mathrm{SF}_{6}-\mathrm{MBW}$ in infants. It is also the largest study to date on $\mathrm{N}_{2}-\mathrm{MBW}$ in $\mathrm{CF}$ infants. The presented data clearly indicate that nitrogen washout is a safe method for infants. Although inhalation of pure oxygen during nitrogen washout lowers tidal volume and minute ventilation (as shown by SINGER et al. [6]), we did not notice any adverse reaction. Unfortunately, the aforementioned work [6] does not comment on the outcome parameters (LCI, FRC). The first direct comparison of both modifications of MBW was performed by GustaFsSON et al. [7] in 10 healthy infants. They reported similar differences in outcome parameters (higher FRC and LCI, lower $V \mathrm{~T}$ during nitrogen washout).

The lower $V \mathrm{~T}$ during nitrogen washout seems to be a consequence of hyperoxic conditions during washout phase ("peripheral chemodenervation") $[8,9]$. Although the $V \mathrm{~T}$ recovers or even exceeds the normoxic values after approximately $60 \mathrm{~s}$, in the end effect, average $V \mathrm{~T}$ is lower compared to normoxaemia. Consequently, assessment of tidal breath parameters during washout phase is inaccurate. Moreover, the increased dead space ventilation makes the washout less efficient and contributes to LCI overestimation. The solubility of nitrogen in blood also interferes with methodology of $\mathrm{N}_{2}-\mathrm{MBW}$. Its back-diffusion may increase washout time and LCI as suggested by SulLivan et al. [10]. Based on these physiological aspects, nitrogen washout cannot estimate ventilation inhomogeneity and end expiratory lung volume (i.e. FRC) as precisely as $\mathrm{SF}_{6}$ washout does. However, in our opinion, $\mathrm{N}_{2}-\mathrm{MBW}$ may still be helpful in clinical setting. As previously shown by our group, $\mathrm{N}_{2}-\mathrm{MBW}$ is capable to reveal poorer lung function in Pseudomonas aeruginosa ever-infected infants [11]. Moreover, compared to $\mathrm{SF}_{6}-\mathrm{MBW}$ it is technically less demanding (no need of this expensive and poorly available gas, its severe greenhouse effect) and consequently more convenient for long-term follow up.

Our results regarding the feasibility of $\mathrm{N}_{2}-\mathrm{MBW}$ are fully comparable to the $\mathrm{SF}_{6}-\mathrm{MBW}$ data published by STAHL et al. They reported feasibility of $67.5 \%$ in children aged $0-3$ years [12] and $78.9-100 \%$ in older children from a multicentric study [13]. JENSEN et al. [14] compared the $\mathrm{N}_{2}-\mathrm{MBW}$ and $\mathrm{SF}_{6}-\mathrm{MBW}$ data in children aged 3-18 years and nitrogen washout proved as a feasible alternative to $\mathrm{SF}_{6}$ washout with similar discriminative power and repeatability. Our data on repeatability of $\mathrm{N}_{2}-\mathrm{MBW}$ in infants are comparable to the data of SINGER et al. [15] from older children. We obtained lower coefficient of variation of LCI in infants, while coefficient of repeatability was slightly higher.

We conclude that $\mathrm{N}_{2}-\mathrm{MBW}$ is an attractive alternative to $\mathrm{SF}_{6}$ washout even in cystic fibrosis infants. It is safe and feasible. Moreover, in some aspects, it may outperform the $\mathrm{SF}_{6}$ method because of its lower cost and lower technical demands of the measurement. The suitability of this variant for longitudinal follow-up is also higher. On the other hand, it must be acknowledged, that $\mathrm{SF}_{6}$ washout offers more precise measurement with respect to a few physiological mechanisms interfering with the methodology of MBW.

TABLE 1 Nitrogen and sulfur washout data summary

\begin{tabular}{|c|c|c|c|c|c|c|c|}
\hline Parameter & $\begin{array}{c}\mathrm{N}_{2}-\mathrm{MBW} \\
(\mathrm{n}=23)\end{array}$ & CV \% & $\operatorname{ICC}(95 \% \mathrm{CI})$ & CR & $\begin{array}{c}\mathrm{SF}_{6}-\mathrm{MBW} \\
(\mathrm{n}=8)\end{array}$ & CV \% & $\begin{array}{l}\text { Comparison for } \\
n=8 \text { ( } p \text {-value) }\end{array}$ \\
\hline $\mathrm{FRC} \mathrm{mL}$ & $315.6 \pm 84.6$ & $3.7 \pm 2.7$ & $0.97(0.93 ; 0.99)$ & $48.3(39.6 ; 62.0)$ & $306.8 \pm 93.6$ & $2.9 \pm 1.8$ & 0.003 \\
\hline $\mathrm{LCl}_{5}$ & $6.4 \pm 0.63$ & $2.8 \pm 2.2$ & $0.85(0.71 ; 0.93)$ & $0.77(0.63 ; 0.99)$ & $6.08 \pm 0.43$ & $1.9 \pm 0.9$ & 0.008 \\
\hline RR breaths $\cdot \min ^{-1}$ & $29.7 \pm 4.6$ & $3.4 \pm 2.4$ & $0.96(0.92 ; 0.98)$ & $4.16(3.40 ; 5.34)$ & $28.3 \pm 3.2$ & $3.8 \pm 1.7$ & 0.305 \\
\hline$V T \mathrm{~mL}$ & $89.9 \pm 28.9$ & $3.6 \pm 4.1$ & $0.98(0.96 ; 0.99)$ & $11.3(9.3 ; 14.5)$ & $106.4 \pm 26.2$ & $2.5 \pm 2.4$ & 0.015 \\
\hline tPTEF/tE \% & $31.7 \pm 10.8$ & $7.5 \pm 4.9$ & $0.86(0.74 ; 0.94)$ & $12.2(10.0 ; 15.7)$ & $32.5 \pm 16.5$ & $6.7 \pm 4.1$ & 0.973 \\
\hline
\end{tabular}

Data stated as mean \pm SD or estimated value ( $95 \%$ confidence interval), unless otherwise stated. The comparison was performed in a subgroup of patients with both $\mathrm{SF}_{6^{-}}$and $\mathrm{N}_{2}$-measurements available $(n=8)$, pair-wise t-test used for calculation. $\mathrm{N}_{2}-\mathrm{MBW}$ : nitrogen multiple breath washout test; $\mathrm{SF}_{6}$-MBW: sulfur hexafluoride multiple breath washout test; CV: coefficient of variation (calculated as 100×SD of the repeated measurements in one patient divided by their mean); ICC: intraclass correlation (calculated as $\left(\sigma_{\text {between }}^{2}\right) /\left(\sigma_{\text {between }}^{2}+\sigma_{\text {within }}^{2}\right)$, where $\sigma_{\text {between }}^{2}$ is the variance of a measured quantity in the study population (variability between subjects) and $\sigma_{\text {within }}^{2}$ is the variance of repeated observations made on one subject (within subject variability); CR: coefficient of repeatability (calculated as $1.96 \times \sqrt{ } 2 \times$ within subject SD); FRC: functional residual capacity; $\mathrm{LCl}_{2.5}$ and $\mathrm{LCl} 5$ : lung clearance index at $2.5 \%$ or $5 \%$ of starting concentration; RR: respiratory rate; $V_{\mathrm{T}}$ : tidal volume; tPTEF/tE: time to peak expiratory flow to expiratory time ratio. 
Further data (e.g. regarding the normative values) are needed before widespread use of $\mathrm{N}_{2}-\mathrm{MBW}$ may be recommended.

Václav Koucký ${ }^{1,2}$, Veronika Skalická ${ }^{1,2}$ and Petr Pohunek ${ }^{1,2}$

${ }^{1}$ Dept of Paediatrics, 2nd Faculty of Medicine, Charles University, Prague, Czech Republic. ${ }^{2}$ Dept of Paediatrics, University Hospital Motol, Prague, Czech Republic.

Correspondence: Václav Koucký, Dept of Paediatrics, 2nd Faculty of Medicine, Charles University and University Hospital Motol, V Úvalu 84, Praha 5, 150 06, Czech Republic. E-mail: vaclav.koucky@seznam.cz

Received: Nov 202017 | Accepted after revision: May 172018

Acknowledgement: We thank all the patients and parents for the participation in the study. Special thanks belong to both Miroslav Koucky (Dept of Applied Mathematics, Technical University of Liberec), and Arnost Komarek (Dept of Probability and Mathematical Statistics, Charles University), who substantially contributed to the statistical analysis. We thank Petra Vancurova (Dept of Paediatrics, University Hospital Motol) for the assistance during lung function measurement.

Support statement: The project was supported by Charles University Grant Agency, grant number 60715 and Ministry of Health, Czech Republic - Conceptual Development of Research Organization, Motol University Hospital, Prague, Czech Republic, number 00064203. Funding information for this article has been deposited with the Crossref Funder Registry.

Conflict of interest: V. Koucký reports grants from Charles University (Charles University Grant Agency, GAUK number 60715), grants from Ministry of Health, Czech Republic (Conceptual development of research organization Motol University Hospital, Prague, Czech Republic, number 00064203), during the conduct of the study; non-financial support for attendance of ECFS conference from Mylan Pharmaceuticals s.r.o., outside the submitted work. V. Skalická reports grants from Charles University (Charles University Grant Agency, GAUK number 60715), grants from Ministry of Health, Czech Republic (Conceptual development of research organization - Motol University Hospital, Prague, Czech Republic, number 00064203), during the conduct of the study; and personal fees from Vertex Pharmaceuticals (for participation on an advisory board for Kalydeco and Orkambi treatment), outside the submitted work. P. Pohunek reports grants from Charles University (Charles University Grant Agency, GAUK number 60715), grants from Ministry of Health, Czech Republic (Conceptual development of research organization - Motol University Hospital, Prague, Czech Republic, number 00064203), during the conduct of the study; and personal fees from Novartis CZ, Teva Pharmaceutical CR and Sandoz, outside the submitted work.

\section{References}

1 Lum S, Gustafsson P, Ljungberg H, et al. Early detection of cystic fibrosis lung disease: multiple-breath washout versus raised volume tests. Thorax 2007; 62: 341-347.

2 Hall GL, Logie KM, Parsons F, et al. Air trapping on chest CT is associated with worse ventilation distribution in infants with cystic fibrosis diagnosed following newborn screening. PLoS One 2011; 6: e23932.

3 Davies G, Aurora P. The use of multiple breath washout for assessing cystic fibrosis in infants. Expert Rev Respir Med 2017; 11: 21-28.

4 Robinson P D, Latzin P, Verbanck S, et al. Consensus statement for inert gas washout measurement using multiple- and single breath tests. Eur Respir J 2013; 41: 507-522.

5 Renee Jensen on behalf of working group: Green K, Gustafsson P, Latzin P, Pittman J, Ratjen F, Robinson P, Singer F, Stanojevic S, Yammine S: Standard Operating Procedure: Multiple Breath Nitrogen Washout, EXHALYZER ${ }^{\bullet}$ D, ECO MEDICS AG, November 2013.

6 Singer F, Yammine S, Schmidt A, et al. Ventilatory response to nitrogen multiple-breath washout in infants. Pediatr Pulmonol 2014; 49: 342-347.

7 Gustafsson PM, Bengtsson L, Lindblad A, et al. The effect of inert gas choice on multiple breath washout in healthy infants: differences in lung function outcomes and breathing pattern. J Appl Physiol (1985) 2017; 123: $1545-1554$.

8 Rigatto $\mathrm{H}$, Desai U, Leahy $\mathrm{F}$, et al. The effect of $2 \% \mathrm{CO}_{2}, 100 \% \mathrm{O}_{2}$, theophylline and $15 \% \mathrm{O}_{2}$ on "inspiratory drive" and "effective" timing in preterm infants. Early Hum Dev 1981; 5: 63-70.

9 Foong RE, Harper AJ, Hall GL, et al. The effect of 100\% oxygen on tidal breathing parameters in preschool children. Eur Respir J 2017; 49: 1601959.

10 Sullivan L, Forno E, Pedersen K, et al. Nitrogen back-diffusion during multiple-breath washout with 100\% oxygen. Eur Respir J. 2017; 50: 1700679.

11 Koucky V, Skalicka V, Martinu V, et al. Do bacterial infection and number of exacerbations have an impact on lung function and nutritional status in the youngest patiens with cystic fibrosis? J Cyst Fibros 2017; S1: 25.

12 Stahl M, Joachim C, Blessing K, et al. Multiple breath washout is feasible in the clinical setting and detects abnormal lung function in infants and young children with cystic fibrosis. Respiration 2014; 87: 357-363.

13 Stahl M, Graeber SY, Joachim C, et al. Three-center feasibility of lung clearance index in infants and preschool children with cystic fibrosis and other lung diseases. J Cyst Fibros 2017; 17: 249-255.

14 Jensen R, Stanojevic S, Gibney K, et al. Multiple breath nitrogen washout: a feasible alternative to mass spectrometry. PLoS One 2013; 8: e56868.

15 Singer F, Kieninger E, Abbas C, et al. Practicability of nitrogen multiple-breath washout measurements in a pediatric cystic fibrosis outpatient setting. Pediatr Pulmonol 2013; 48: 739-746. 